\title{
Metastatic Ewing Sarcoma
}

National Cancer Institute

\section{Source}

National Cancer Institute. Metastatic Ewing Sarcoma. NCI Thesaurus. Code C7807.

Ewing sarcoma which has spread from its original site of growth to another anatomic site. 